\title{
PESQUISA COM CRIANÇAS: ALGUMAS QUESTÕES DE GÊNERO NA EDUCAÇÃO INFANTIL
}

Flávia Miller Naethe Motta ${ }^{(*)}$

\section{INTRODUÇÃO}

Com um passado de pesquisas na área da infância e das crianças, as indagações que deram início às questões ora tratadas buscavam a análise das relações de poder travadas no interior das brincadeiras entre as próprias crianças - as estratégias de negociação, a escolha/definição dos papéis encenados, a concepção das regras que definem a condução das atividades - ou seja, que relação as práticas de poder e hierarquia internas à brincadeira estabelecem com a cultura mais ampla e o que fala da sociedade esta forma específica de inserção da cultura da infância.

Desde o princípio, realizar pesquisa com as crianças demandava o rompimento com uma lógica adultocêntrica revelando que, para entender o que falavam, seria necessário um mergulho na sua realidade, de maneira a apreender as "categorias nativas" que dessem pistas sobre os significados próprios atribuídos ao contexto que vinha analisando. Geertz (1989) contribui ao definir cultura como um conjunto de códigos e convenções simbólicas onde as mediações são feitas fundamentando relações de sentidos explícitos e implícitos, segundo os significados dados em cada momento. É em função disso que a cultura pressupõe que um campo semântico seja partilhado para que possa ser lida e seus sentidos interpretados, partindo do pressuposto que [...] O homem é um animal amarrado a teias de significados que ele mesmo teceu" e continua: "assumo a cultura como sendo essas teias e sua análise; portanto, não como uma ciência experimental em busca de leis, mas como uma ciência interpretativa, à procura do significado" (p. 15).

Os sistemas possíveis de significação constituiriam as culturas infantis a partir das quais as crianças atribuiriam sentido às práticas sociais que poderiam ser vistas, dessa forma, como práticas de significação.

A compreensão a respeito das culturas infantis trouxe como consequência a percepção que que numa pesquisa com crianças, quanto antes se desse a entrada em campo, maiores as chances de apreensão dos elementos simbólicos nele presentes.

\footnotetext{
(*) Doutora em Educação pela Pontifícia Universidade Católica (PUC Rio), professora associada da Universidade Federal Rural do Rio de Janeiro (UFRRJ), professora permanente do Programa de Pós-Graduação em Educação, Contextos Contemporâneos e Demandas Populares.E-mail: flaviamnmotta@gmail.com.
} 
Paralelamente, a compreensão fundamentada em Bakhtin, de que a abordagem dos sujeitos da pesquisa pelo pesquisador é um ato dialógico, acarretava pensar que, quanto antes iniciado o diálogo, antes se daria a produção de sentidos, uma vez que a especificidade das ciências humanas precisa considerar que elas tratam da relação entre o pesquisador e sujeitos expressivos, falantes. Aquele que busca conhecer não faz a pergunta a si mesmo ou a um terceiro na presença de um objeto mudo, coisa morta, mas o faz diretamente àquele que pretende conhecer (2011, p. 394).

As dimensões ética e estética, nessa abordagem, precisam se conjugar nas ciências humanas para se articularem à epistemológica - arte, vida e conhecimento. A tripla dimensão da cultura atravessa tudo na existência humana e vai marcar os atos como irrepetíveis e de total responsabilidade do sujeito.

Arte, vida e conhecimento unidos na dimensão da cultura era a bagagem com a qual chegava à escola. Durante o primeiro ano convivi com a realidade da turma do Infantil $5^{1}$.

Foi pelo campo que tudo começou. As perguntas foram se apresentando à medida que as observações avançavam. Inúmeras reflexões buscavam clarear a opção metodológica que se configurava. Esse artigo apresenta as consequências do ingresso precoce no campo sobre o desenvolvimento das questões norteadoras da pesquisa e argumenta a favor de uma metodologia que considere os aspectos culturais, logo de significação, decorrentes do encontro dos sujeitos.

\section{A PESQUISA COM CRIANÇAS NUMA INSPIRAÇÃO ETNOGRÁFICA}

Tomar de empréstimo uma metodologia de outro campo de conhecimento, adaptando-a à realidade da pesquisa educacional fez despontar alguns embates entre os campos da antropologia e os pesquisadores em educação. Há que se ter cuidado para que a apropriação não descaracterize o fazer consolidado de uma área de saber. Até porque, concordamos com Bordieu (1983, p. 123) quando afirma que o "universo da mais pura ciência é um campo como qualquer outro, com suas relações de força e monopólios, suas lutas, estratégias, interesses e lucros."

André (1992) defende uma perspectiva etnográfica que vá além de um estudo da categoria, por ela denominada (1992, p. 31) de "cotidiano escolar", ao qual dirige a crítica de que se limita ao relato dos fenômenos e não à sua compreensão, sugere a necessidade de "ir além do concreto aparente" (p. 32). Não pretendo entrar nesse debate, até porque o campo dos estudos do/no/com cotidiano (OLIVEIRA, 2007;2009) avançaram e se consolidaram como um fazer teórico-

\footnotetext{
${ }^{1}$ Turma de Educação Infantil, composta de crianças com 5 anos de idade a se completar até 31 de março do ano em questão.
} 
metodológico. Na época, entretanto, da produção de André, o que a autora criticava era a necessidade de buscar a significação dos dados coletados que, ao se articular com as dimensões mais amplas da sociedade onde aquela instituição escolar se situava, permitia a ampliação da compreensão da cultura escolar ali observada.

Sem dúvida os instrumentos etnográficos têm sido de muita valia na pesquisa educacional (MATTOS e CASTRO, 2011) sendo cada vez mais utilizados desde os anos 80 do século passado. Entre eles, podemos destacar a observação participante, as entrevistas, o uso de imagens de vídeo, história de vida, questionários, fotografias entre outros.

A inspiração etnográfica foi a expressão adotada então pelos pesquisadores em educação, como saída negociada para a não apropriação de um fazer antropológico, mas ao mesmo tempo, reconhecendo a sua filiação uma vez que:

A pesquisa etnográfica inclui [...] necessariamente, a observação participante, o participante como protagonista da pesquisa, a imersão na cultura local por prolongado período de tempo, a busca por eventos típicos e atípicos e a análise por processos indutivos. (MATTOS e CASTRO, 2011, p. 35).

Quando os sujeitos da pesquisa são crianças torna-se importante considerar ainda que se trata de um campo de saber relativamente novo que se consolidou como a sociologia da infância. Em pesquisa anterior (MOTTA, 2013) verifiquei que, segundo Sarmento (2008), o debate que marcou o reconhecimento das crianças como agentes sociais foi superado. E, que elas, enquanto objeto de estudo sociológico, já estão afirmadas em um campo do saber.

Se o conceito de culturas (escolar, infantis, docentes) marca a etnografia educacional, é preciso explicitar como o estamos considerando. Se inicialmente nos apoiamos em Geertz (1989), agora é preciso articular sua proposta, de campo semântico compartilhado, às especificidades das crianças. O que há de específico nas culturas infantis? A reprodução interpretativa (CORSARO, 1997), a cultura de pares (2009) e a cultura lúdica.

A reprodução interpretativa mostra que "as crianças criam e participam de suas culturas de pares singulares por meio da apropriação de informações do mundo adulto de forma a atender seus interesses próprios enquanto crianças" (CORSARO, 2009, p. 31). O termo reprodução remete a algo que transcende uma imitação, trata-se de produzir de novo, atribuindo novas significações, apropriando-se de aspectos ainda não incorporados em seu repertório, algo relativo ao desenvolvimento proximal de que nos fala Vigotski (1998, p.111). Ao mesmo tempo que produz 
novamente os conceitos, isso se dá de forma interpretativa. Esta proposição rompe de vez com a perspectiva de socialização como inculcação de valores (DURKHEIN. 1994).

A cultura de pares, por sua vez diz respeito a "um conjunto estável de atividades ou rotinas, artefatos, valores e interesses que as crianças produzem e compartilham na interação com seus pares" (CORSARO, 2009, p. 32). A escola pela possibilidade de contato frequente das crianças entre si é um lócus privilegiado da sua ocorrência, embora não seja definitivamente o único.

Finalmente, a cultura lúdica, termo cunhado por Brougère (1998), é o repertório compartilhado numa da cultura que permite compreender como brincadeira algo que para estranhos poderia não fazer o menor sentido. Compõe-se dos elementos que permitem o faz-de-conta que produz uma realidade diferente daquela da vida quotidiana: os verbos no imperfeito, as quadrinhas, os gestos estereotipados do início das brincadeiras compõem assim aquele vocabulário cuja aquisição é indispensável ao jogo (p. 4)

Apoiada nos conceitos teóricos que nos levam a considerar as crianças como um grupo a ser pesquisado, fui em busca dos aspectos metodológicos que possibilitassem a entrada em campo. Corsaro (2005) sinaliza para a desigualdade etária entre pesquisador e sujeitos que pode levar a uma relação de poder hierárquica e controladora. Para a superação destas barreiras o sociólogo propõe algumas estratégias que, se não eliminam e impossibilidade concreta de tornar-se um nativo, minimizam seus impactos de forma a possibilitar o compartilhamento com as crianças de suas culturas infantis.

A ideia de "entrada reativa" foi uma resposta à percepção do quanto os adultos são diretivos nas suas interações com as crianças. Esperar, estar lá, deixar o contato acontecer parece ter sido uma saída eficiente para uma aproximação com as crianças.

Corsaro propõe então que o pesquisador interessado em pesquisa com crianças pequenas deve tomar alguns cuidados para constituir-se naquilo que ele denominou "adulto atípico" (2005, p. 451): não iniciar ou terminar brincadeiras, assumir papéis secundários nos jogos de faz de conta, não intervir em conflitos, enfim, embora um adulto, abrir mão do poder que tal condição lhe confere.

Munida de tais artefatos metodológicos, fui ao campo encontrar as crianças. 


\section{A PESQUISA}

A escola foi indicada pela Secretaria Municipal de Educação do município de Três Rios, do Estado do Rio de janeiro durante três anos. Nos dois anos iniciais, a ida era semanal, desde o horário de entrada até o da saída. No último, foram feitas algumas visitas para acompanhamento das crianças.

O começo da pesquisa caracterizou-se metodologicamente como um "encontro" na concepção definida por Passos (2014, p. 234).

Entendemos o encontro, na pesquisa em Ciências Humanas e Sociais, como uma experiência de interação entre sujeitos, que pode ser produzida/ organizada/promovida pelo pesquisador, ou pode se dar ao acaso. Ao longo dos trabalhos desenvolvidos foi possível observar que no processo da pesquisa acontecem encontros entre sujeitos que vão suscitar outros encontros e outros encaminhamentos para a produção do conhecimento. [...] A emergência de saberes, de relações, de narrativas é grandiosa no momento em que um sujeito "é afetado pelo outro" e que este "afetar-se" gera conhecimento. Esses encontros assim têm significado experiência no sentido daquilo que "nos afeta", que "nos modifica" [...], modificando nossas práticas e nossa linguagem. Esse compartilhamento da experiência de agra mudança de comportamento e de pontos de vista em ambas as partes, fazendo o sujeito ressignificar o outro na mesma medida em que se ressignifica. Este é nosso critério: para nomear um contato entre sujeitos de "encontro" no processo da pesquisa, é preciso que esse "deixar-se afetar pelo outro" aconteça e que isso se transforme em linguagem.

Para que o encontro com as crianças se desse e propiciasse a imersão em suas culturas dediquei atenção especial à entrada em campo, consciente de que eventualmente a minha aceitação demoraria algum tempo. A participação nas brincadeiras seguiu à risca as recomendações para o adulto atípico. Não cabia mim a iniciativa de propor conversas, brincadeiras e, muito menos, resolver conflitos entre as crianças. Busquei sempre assumir uma atitude coadjuvante: não liderava nas brincadeiras, não exercia os papéis de mãe ou professora, não dava início ou fim às brincadeiras. Após um tempo, depois de aceita pelo grupo, caso saísse do comportamento esperado, era chamada atenção por eles.

As observações foram realizadas em momentos de sala de aula, pátio, refeitório, entrada e saída, festas comemorativas da escola. Várias foram as conversas informais com as professoras e elas estão relatadas no diário de campo. Os diálogos travados com as crianças estão, da mesma forma, registrados. Os espaços, os murais, os deslocamentos pela escola também foram objeto de 
análise. A secretaria escolar permitiu acesso às fichas dos alunos e, no primeiro ano de observação as profissões dos pais e sua renda em salários mínimos foram tabuladas.

Para este artigo, optei por focalizar o primeiro ano da pesquisa, onde, pelo fato de estarem ainda na Educação Infantil, havia mais tempo de brincadeiras e atividades livres que ampliavam as possibilidades de observação das culturas de pares e a emergência de algumas categorias de análise interessantes, dentre elas as que aqui destaco: questões de poder e gênero.

Ao chegar, fui apresentada à turma pela professora durante a roda de conversa e falei que estava estudando como as crianças brincavam, se durante as brincadeiras brigavam e como resolviam quando isso ocorria e por isso, iria participar de suas atividades, observando e anotando, uma vez por semana até o final do ano. A princípio fui meio ignorada, as crianças não manifestaram muito interesse, embora eventualmente olhassem para mim e para o meu caderno. Neste dia, além da professora, somente uma criança me dirigiu a palavra, na verdade mais como forma de estabelecer uma comunicação do que com algum interesse. Ela perguntou se eu estava escrevendo e eu respondi que sim. Esse foi todo o diálogo da pesquisadora com os seus sujeitos nesse primeiro encontro.

Aos poucos, entretanto, comecei a ser integrada ao grupo.

Embora o objetivo inicial fosse observar as relações de poder entre as crianças, os imponderáveis do campo (MALINOWISKI, 1978) revelaram, já nas primeiras anotações, uma diferença relevante nas ações dos meninos e das meninas. Não seria possível agrupá-los no contexto de comportamentos infantis sob o risco de incorrer em generalizações que acabariam por esvaziar os conceitos de análise. As diferenças entre os comportamentos dos meninos e das meninas eram construções sociais. Tornou-se necessário à pesquisadora o recurso aos estudos de gênero.

As crianças constroem uma identidade partilhada nas interações - o sentido de ser criança naquelas condições concretas - ao mesmo tempo em que estabelecem dimensões particulares e estruturais específicas que as hierarquizam entre si em suas experiências subjetivas. São elas: gênero, idade e classe social, formadores de "identidades particulares que as assemelham e unem elou diferenciam e separam entre si." (FERREIRA, 2002, p. 113-114, grifo da autora).

Ao reler as notas do diário de campo ficou claro que, desde o primeiro encontro, já eram visíveis as questões de gênero, tanto na fala da professora quanto das crianças. Custei um pouco a enxergar isso, pois me encontrava capturada na ideia de relacionar "criança" e poder de tal forma, que não enxergava as suas concretudes (classe, raça, gênero) nas quais tanto insiste a sociologia da infância. 
Carmen $^{2}$ me apresentou para as crianças através da escrita do meu nome. Elas tentavam dizer as letras à medida que a professora as escrevia em caixa alta. Ela confirmou o acento agudo. Sentei no chão, na roda, me apresentei, falei que estudava, pesquisava e observava como as crianças brincavam. Carolina disse que eu era "observadora".

Carmen perguntou: "O que eu desenho hoje para as meninas?" Meninas: "Boneca, flor..." Carmen: "Eu já desenhei isso essa semana... vou fazer uma borboleta, tá?"

Meninas: "Sim!" Carmen: "E para os meninos?" Meninos: "Homem aranha" Carmen: "Eu não desenho tão bem. Vou fazer uma teia e uma aranha, tá bom?” (Diário de Campo).

O conceito de gênero surgiu simultaneamente como uma ferramenta política e analítica (LOURO, 1997, p. 21). Sua perspectiva permitia afastar um determinismo biológico implícito na ideia de diferença sexual. Dessa forma, o gênero tornou-se elemento constituinte da identidade dos sujeitos, articulando-se aos de raça, classe e nacionalidade.

É comum uma "naturalização" das diferenças que apaga o processo histórico de sua construção, entretanto, o corpo é alvo das ações disciplinadoras e não pode ser capturado pelas categorias de feminino e masculino, tipicamente binárias.

A educação infantil cuida e educa os "corações e mentes", ou seja, há uma ação que também educa os corpos, ainda que pareça que eduque para a sua submissão ao intelecto, negando suas necessidades e peculiaridades em nome de uma "agenda coletiva" que indica quando ter fome, quando descansar, de que forma se posicionar, falar, sentar...

Se as crianças estão imersas na cultura desde o princípio, na escola encontram uma oportunidade de socialização pela cultura de pares. Observá-los em seus "jogos de papeis" permite ver de que forma se apropriam do que a cultura da diferença dos gêneros propõe para o que é "ser menino" e o que é "ser menina" numa perspectiva social evidentemente heteronormativa.

João começou uma brincadeira de ser um bicho feroz. Ele deitava no chão e os demais vinham provocar, então o bicho feroz corria para pegar aqueles que o estavam incomodando. Luís falou para João: "Posso brincar?" João o ignorou e disse para Rômulo: “Ah não Rômulo, ah não...” E para Antônio: “Tá bom, você é bicho normal." João se deitou no chão e cedeu ao Rômulo: "Então tá, nós vamos lá para casa." Luís se dirigiu para o Rômulo: "Rômulo me deixa brincar?" //Como João

\footnotetext{
${ }^{2}$ Os nomes utilizados são fictícios para preservar a identidade dos sujeitos.
} 
aceitou Rômulo para seu "time", Luís buscou uma aceitação do segundo no comando// Rômulo nem hesitou: "Não." João mostrou quem mandava: "Ô Antônio, você tem que pegar a gente!” Antônio, aceitando a liderança, esclareceu: “O que eu tenho que fazer mesmo?” João e Rômulo responderam juntos: “Cutucar a gente!” O jogo de aproximação/evitação começou. Ao ser perseguido, Antônio subiu na mesa. João e Rômulo permaneceram no chão, rugindo ameaçadoramente, de quatro, respeitando a área sobre a mesa como segura.// Se desejassem, bastava levantar e pegar o Antônio.// (Diário de campo).

Nos eventos ficam evidentes as relações de poder nas interações entre as crianças. Nas brincadeiras, as crianças demostram liderança e exercem sua autoridade de maneira impositiva, autoritária, demonstrando uma forma peculiar de entendimento dos valores da sociedade na qual estão inseridas. Para melhor compreender o que se afirma, explicitamos a maneira como o conceito de poder está sendo adotado. Foucault (1977) propõe a substituição de uma "teoria" do poder pela sua "analítica". Em sua forma mais abstrata, o conceito foucaultiano não mantém nenhum contato com os conceitos de Estado, soberania, lei e dominação. Ele consiste em relações de força, e não emana de um ponto central, mas sim de instâncias periféricas. Além disso, está, ao mesmo tempo, em toda parte, na relação de um ponto com outro, enfim multiplica-se e provém, simultaneamente, de todos os lugares. Assim, podemos considerar o poder como uma rede capilar que atravessa a sociedade como um todo, ele seria antes uma estratégia do que um princípio ou atributo. É importante que observemos os seus efeitos manobras, táticas, técnicas fundamentais.

Entre os meninos, as manifestações de poder apontavam para uma expressão clara e explícita de seu exercício. Não fica dúvidas sobre quem está no comando e o que eles desejam ou não que aconteça na brincadeira. Trata-se de uma dada apropriação do que significa ser "homem" na cultura em que estão inseridos. Espera-se deles, clareza, firmeza, força, virilidade. Quase uma caricatura que exagera e dá ênfase aos traços assumidos como valor no comportamento masculino. Mas, o conceito de gênero é relacional, explica as relações sociais entre homens e mulheres, assim, cabe às meninas um comportamento, se não oposto, ao menos ambíguo em relação às maneiras de exercerem sua autoridade e poder no grupo. Podemos ver isso ocorrendo no exercício de exclusão e inclusão do evento a seguir que, através de mensagens pouco diretas, não esclareciam sobre a aceitação da menina no grupo ou não.

Catarina abriu a mochila e tirou um telefone de brinquedo de dentro dela, ele fazia sons de toque e dizia uma mensagem em inglês. Imediatamente, virou o centro das atenções das meninas. Todas passaram a falar com ela com respeito. Thalita pediu: "Me empresta?" Mas foi ignorada. Catarina mostrou o telefone, colocou no ouvido 
das colegas e no meu e deixou Júlia segurar. Carolina pediu: "Você me empresta depois dela?" Catarina percebeu que Thalita estava chateada e retomando o telefone aproximou de seu ouvido, mas ela recusou. Catarina deu o telefone para Vanessa. (Diário de Campo).

A educação dos corpos é também a educação dos gêneros, nem sempre explícita ou intencional, porém permanente e eficaz. É comum o reforço aos estereótipos de gênero por parte dos adultos que se relacionam com as crianças.

O minucioso processo de feminilização e masculinização dos corpos, presente no controle dos sentimentos, no movimento corporal, no desenvolvimento das habilidades e dos modelos cognitivos de meninos e meninas está relacionado à força das expectativas que nossa sociedade e nossa cultura carregam. (VIANNA e FINCO, 2009, p. 272).

A relação com o espaço e com o tempo também sofre o constrangimento do binarismo dos gêneros não compreendidos em sua gênese histórico-cultural, mas vivido como fenômeno ideológico. Assim, quanto à ocupação espacial das brincadeiras foi possível perceber que, enquanto os meninos se "espalhavam" por toda a sala de aula, as meninas estabeleciam uma base fixa para suas brincadeiras com limites espaciais bem definidos, quase fronteiras territoriais. As meninas ficavam sempre numa mesma mesa, enquanto os meninos ocupavam as demais e o espaço entre elas (a sala tinha 5 mesas redondas para grupos de 4 crianças cada).

Os meninos são estimulados a ocuparem os espaços a realizarem movimentos amplos, a não se deterem diante de obstáculos, ainda que o obstáculo seja um grupo de meninas brincando em seu caminho. As expectativas, que se fundamentam ideologicamente na diferença biológica tendem a produzir jeitos de ser distintos e opostos, ainda que as crianças resistam e transgridam o que lhes é imposto, permanece a visão da regra sobre o que é tomado como exceção que acaba por se tornar objeto de estudo a ser comparado com o que é tomado como o coletivo regular.

As meninas, por sua vez, se conformavam a uma geografia de fronteiras bem mais limitadas e a uma postura de defesa de território, ao invés do avanço para o espaço dos outros.

Rômulo e Kauã vieram ao centro da sala com uma corda de pular e entraram no meio da nossa brincadeira. O objetivo passou a ser a tampinha atravessar de um lado ao outro, por baixo da corda. Antônio assumiu o lugar do Kauã que foi chamado pela professora para arrumar um jogo que ele tinha deixado desarrumado. A brincadeira se desorganizou e os dois grupos se misturaram. As duas brincadeiras estavam atravessadas. João falou: Eu sou o leopardo eu furo a garganta! E rugiu bem alto. 
Wesley parecia aborrecido com a invasão do nosso espaço, Richard se aproximou dele. Luís afastou o Renan, com quem brincava antes, dizendo: Só eu e o Antônio estamos brincando, caraca! (Diário de Campo).

A relação com o tempo também revela especificidades. As meninas, de maneira geral, despendiam muito mais tempo na organização da brincadeira - chegando a ocupar quase toda a duração da atividade livre. Os meninos, por sua vez, planejavam rapidamente o que seria desempenhado e davam início à atividade.

Já o exercício de poder entre as meninas se configurava em um jogo para qual elas demonstraram preparo diferenciado; Catarina não manipulava tão bem quanto Júlia o oferecer e tomar que se fazia necessário.

Vanessa pegou a Barbie, quando Catarina viu, deu uma bronca: "Deixa minha Barbie aí!" Vanessa, ressentida, se afastou. Vanessa aproximou-se de Giovana e as duas chamaram Thalita. Com isso, Catarina ficou só e Júlia também perdeu espaço. Rapidamente ela reagiu: "Está dormindo? Está dormindo? Quer ver?" Ninguém deu muita atenção. Júlia colocou a boneca sobre a mesa, Thalita rapidamente a pegou. Júlia tomou de volta e reclamou: "Você está desmontando!" Catarina resolveu deixar sua Barbie com a Vanessa. (Diário de Campo).

Ao final deste evento, percebemos que Catarina aprendeu, durante a interação, estratégias que demonstravam um maior entendimento das regras do jogo.

Os objetos de consumo e as relações que as crianças estabeleciam com eles também traziam peculiaridades relativas à diferença de gênero. Para os meninos, importava mostrar o objeto, estabelecer comparações, caso outro menino tivesse objeto semelhante e aí então, definir quem saía vencedor nessa disputa:

$\mathrm{Na}$ mesa que eu observava, começou uma comparação do tamanho do lápis. Os meninos colocavam seus lápis de pé sobre a mesa e os mediam. // Não pude deixar de pensar que os meninos estão sempre comparando quem é o mais poderoso.// Luís aproximou-se e perguntou ao João se ele tinha um lápis verde com borracha igual ao do Júlio César. João respondeu que tinha. (Diário de Campo).

Já com as meninas, o padrão de disputa remetia a um objeto ausente, logo produto da imaginação ou do desejo do interlocutor: 
Pedi licença às meninas e sentei-me com elas. Na mesa estavam Júlia, Catarina, Vanessa, Carolina, Thalita, Ludmila e Giovana. Júlia e Catarina discutiam porque Júlia acusou a amiga de ter levado uma boneca sua para casa. Catarina respondeu que tinha deixado na escola. Júlia quis saber: Você mora aonde?

Júlia pegou sua boneca nova na caixa e o seu segundo vestido, Thalita pediu para trocar, mas Júlia não deixou. Vanessa foi à outra mesa buscar massa de modelar a pedido de Catarina, que brincava com uma Barbie e retornou. Júlia ordenou para Ludmila: "Coloca!” Ludmila surpresa perguntou: "O quê?"

Júlia: "O vestido!" // Nesse momento havia uma divisão na mesa que agrupava de um lado Júlia, Carolina e Ludmila e de outro, Catarina, Giovana e Vanessa. Thalita estava, aparentemente, sem filiação a nenhum dos dois grupos.// Júlia retirou a caixa da boneca da sacola de supermercado onde estava e começou um jogo de só mostrá-la ao seu grupo. Obviamente despertou o interesse de todas as meninas que estavam na mesa. Júlia falou para Catarina: "Vai se meter?" Catarina não se intimidou: "Estou vendo por ali!" Júlia escondeu mais a caixa com a sacola plástica. Foi a vez da Vanessa: "Estou vendo aqui." Júlia respondeu com rispidez: "Não deixa!” Deu um murro na mesa e continuou: "É minha boneca! Guardando a caixa no saco plástico." Catarina, Vanessa e Giovana estavam fascinadas pela caixa que não podiam ver, mas não se deram por vencidas: "Estamos vendo porque o plástico é transparente." Carolina pegou a sacola e deixou Ludmila ver. Júlia se levantou e foi até a professora pedir que ela colocasse o vestido. O grupo de Júlia - Ludmila e Carolina - continuava a defender a caixa do olhar das demais. O outro grupo resolveu, então reagir e escondeu a Barbie atrás da mochila. Vanessa começou a contar vantagem, disse que iria ganhar um celular, uma boneca, um computador, um batom e um brilho. (Diário de Campo).

O comportamento das meninas, nessas ocasiões, referia-se a algo que não podia ser visto naquele momento. Havia uma insinuação de propriedade de algo de valor que despertava o interesse das demais. Pela quantidade de objetos que Vanessa traz para o final do diálogo é possível estimar o quanto estava interessada em ver a boneca da colega. O comportamento que prevalecia era, em certa medida, sedutor, em oposição ao dos meninos que era de exposição.

Tal como para Ferreira (2002), ficou evidente que as crianças do terceiro período traziam para a escola valores simbólicos de gênero: 
que thes estão previamente associados e/ou que thes foram inscritos pelas crianças nos usos sociais e reconceptualizações através das rotinas do brincar - saber o que brincar, onde brincar e a quê, como, com quê e com quem brincar -, subscreve a ideia de que meninas e meninos têm um conhecimento semelhante dos recursos disponíveis para a expressão de identidades de género, que se organizam de modo segregado e em torno do seu próprio género. (p. 115)

Esse conhecimento não significa que as crianças se apropriem dos valores de gênero tal como os adultos. Assim, a autora distingue entre a adoção de papéis de meninos ou meninas e a identidade de cada um. No primeiro caso trata-se de desempenho de papéis arbitrariamente definidos, enquanto a identidade iria além, daria sentido ao pertencimento relacionando múltiplas dimensões. Ferreira propõe que a relação das crianças, neste aspecto, permite um novo posicionamento analítico que desconstrói a polaridade decorrente de uma lógica simplista baseada na oposição entre dois pólos: um dominante, um dominado. A maneira peculiar das crianças ressignificarem os papéis de gênero coloca em questão a unidade e a permanência da sua relação.

[...] introduzindo de permeio as redes complexas de poder que, no seu exercício, nas suas estratégias, nos seus efeitos, nas resistências que desencadeia, não só são constitutivas das hierarquias sociais entre géneros, como podem, ao fracturá-las e dividi-las internamente, surpreender as múltiplas formas que podem assumir as masculinidades e as feminilidades [...] (2002, p. 116).

O conceito de posicionamento permite a compreensão de que os modos possíveis das crianças construírem e assumirem o gênero, não decorrem da influencia biológica concreta, sequer de uma determinação social abstrata, mas se revelam em ações dadas. As crianças, nas suas próprias experiências, ao interpretarem o mundo em termos de um conhecimento de gênero "são capazes de se posicionar de variados modos no seio de um conjunto de discursos e práticas e aí desenvolver subjectividades, tanto em conformidade como em oposição face aos modos pelos quais os outros também as posicionam.” (2002, p. 117).

As zonas de transgressão de gênero (FERREIRA, 2002, p. 120) levam ao reconhecimento das variações possíveis introduzidas pelas crianças quando as fronteiras são ultrapassadas e se tornam áreas de conflito, permitindo uma analise privilegiada das negociações que daí decorrem. $\mathrm{O}$ conceito de liminaridade, de Van Gennep (1978), ajuda a pensar a respeito de duas crianças desta empiria em especial: Júlio César e Paula. Os dois transitavam com desenvoltura tanto pelo grupo de meninos quanto pelo de meninas. Transgrediam as expectativas lineares do que é ser menino e o que é ser menina. Para este autor, o sujeito "transitante" é aquele que está de passagem de um status ou lugar a outro: "Qualquer pessoa [...] que flutua entre dois mundos. É esta situação que 
designo pelo nome de margem ...." (p. 36). Com Turner, percebemos o quanto tais atributos “... são necessariamente ambíguos... esta condição e estas pessoas furtam-se ou escapam à rede e classificações que normalmente determinam a localização de estados e posições num espaço cultural. (1974, p. 116). Vemos em Paula que ela apresentava algumas características que a distinguiam da expectativa do que é ser menina: não se queixava à professora sobre o comportamento dos demais, falava pouco, não era chorona e colaborava com os meninos.

Em nossa mesa, André ofereceu mais massa de modelar para Paula, ela aceitou, ele jogava pedaços para ela e depois os pegava de volta, ela não reclamou. Os meninos, do outro grupo, deitaram-se nas fileiras de cadeiras. Paula pegou uma cadeira de nossa mesa e arranjou-a na ponta da fileira, dizendo: Aqui ó! // Embora mostrasse interesse na brincadeira dos demais, continuava em seu lugar, mostrando uma atitude de colaboração "desinteressada". (Diário de Campo).

Já Júlio César apresentava outra estratégia para conseguir acesso às brincadeiras dos dois grupos. Neste evento é possível observar o motivo que o distinguia dos demais, sua coragem ao lidar com insetos:

Júlio César encontrou uma cigarra, virada de barriga para cima, perto do bebedouro e pegou o animal, Carolina e Vanessa hesitavam entre o medo e o interesse, Rubens e Antônio também não estavam confiantes para segurar o inseto nas mãos. Júlio César organizou uma brincadeira de fazer a casinha da cigarra e todos começaram a ajudar. Depois de um tempo a cigarra voou para a quadra e Sandra proibiu as crianças de irem lá. (Diário de Campo).

Uma estratégia das meninas observadas para livrar-se dos meninos em situações de tensão ou disputa era questionar a sua masculinidade. De acordo com Barreto e Silvestri, pode-se dizer que os meninos precisam constantemente reafirmar, não a sua masculinidade, mas sim, seu distanciamento da feminilização, estado no qual as características do "macho" se apresentam debilitadas:

Um homem, na nossa cultura ocidental globalizada é submetido a um processo de socialização, durante o qual vai adquirindo as referências de comportamento que moldam a conduta do masculino. Entretanto, a condição de masculino, o status de homem macho, diferentemente, do lugar do feminino, não é confirmado, em caráter definitivo. (2005, p 12).

$\mathrm{O}$ evento a seguir demonstra o que as autoras apontam em seu texto. Um menino interessarse por uma boneca nega sua masculinidade não só pela dimensão do feminino; a oposição que aqui se estabelece refere-se à homossexualidade. 
Thalita interessou-se pela tiara de massa de modelar que Catarina fez para a Barbie, enquanto isso, Giovana e Carolina observavam a brincadeira de luta dos meninos, sorrindo. A brincadeira dos meninos ficou muito bruta e barulhenta. Giovana levantou-se e veio contar um segredo para Thalita. Os meninos pegaram o saco plástico que envolvia a caixa da boneca da Júlia. Giovana jogou a boneca e a caixa no chão, aproveitando que Júlia tinha saído e quando ela voltou, disse que tinha sido o Rubens. Júlia pegou o saco, mas João arrancou de sua mão dizendo: "Eu vi primeiro!” Júlia foi queixar-se com a professora. Carmen deu o comando para irmos para o pátio. Quando Richard passou pela mesa das meninas, colocou a mão na boneca e Catarina ameaçou: "Vou contar para o seu pai! Você está mexendo na boneca, isso é coisa de menina ou de bichinha!" (Diário de Campo).

\section{CONSIDERAÇÕES}

É possível perceber que relacionar o exercício de poder às questões de gênero traz uma complicação conceitual, entretanto, ela pode enriquecer os seus termos:

Os sujeitos que constituem a dicotomia não são de fato, apenas homens e mulheres, mas homens e mulheres de várias classes, raças, religiões, idades etc. e suas solidariedades e antagonismos podem provocar os arranjos mais diversos, perturbando a noção simplista e reduzida de homem dominante versus mulher dominada. (LOURO, 1997, p. 33).

Por outro lado, trazer o debate para a escola implica em reconhecer o seu papel de instituição formadora, estrategicamente situada na vida dos sujeitos para introduzi-los na ordem social por meio do poder disciplinador. Evidentemente outras instituições colaboram nesse processo, mas, interessa identificar o seu papel. Para Foucault (1977), a disciplina se organiza como uma tecnologia que age sobre os corpos dos indivíduos, controlando-os e assujeitando suas forças na produção de comportamentos. A escola desempenha papel crucial nesse processo, pois, não só é o palco onde essas experiências se realizam, como também um agente que as confirma e produz. As aprendizagens são naturalizadas de forma que os fatos sociais perdem a dimensão histórica de reconstrução permanente.

O conceito da sexualidade pôde ser construído na idade moderna junto à ideia de individualidade, que trouxe consigo a noção de subjetividade como sua constituidora. Como objeto de estudo, a sexualidade emergiu no campo da reprodução biológica e social das populações. Freud e a psicanálise iniciaram uma forma de pensar a sexualidade estruturada à identidade que, segundo Abramovay (2004, p.30) faz parte do imaginário popular da cultura ocidental até hoje em dia. 
A segunda metade do século $\mathrm{XX}$ trouxe mudanças significativas provocadas pelo desenvolvimento de métodos contraceptivos, desvinculando o ato sexual da atividade reprodutiva, e dos movimentos sociais que:

questionavam as desigualdades resultantes das relações de poder construídas a partir de materialidades de vida em relações sociais, valores e representações simbólicas derivadas dos modelos de normalidade sexual vigentes até então. (ABRAMOVAY, 2004, p. 31).

As relações entre escola e sexualidade decorrem, em parte, do fato de que as construções das identidades de gênero são fenômenos pertencentes ao desenvolvimento, o que deslocaria para esse local uma premência em trabalhá-los. Foucault (1988, p. 66 - 67), entretanto, já apontava para a existência de duas maneiras de apropriação da sexualidade: a ars erótica e a scientia sexualis. $\mathrm{Na}$ primeira, a ênfase se centraria na questão do prazer e da subjetividade, enquanto para a Segunda enfatiza o discurso científico e a preocupação com a reprodução. A apropriação do discurso pedagógico sobre a sexualidade estaria extremamente volltado para essa segunda via, com ênfase no controle e prevenção.

De qualquer forma, vemos com Louro que:

É indispensável admitir que a escola, como qualquer outra instância social, é, queiramos ou não, um espaço sexualizado e generificado. Na instituição escolar, estão presentes as concepções de gênero e sexuais que, histórica e socialmente, constituem uma determinada sociedade. A instituição, por outro lado, é uma ativa constituidora de identidades de gênero sexuais. (1998, p. 87-88).

A ação dos mais velhos na formação das identidades sexuais aparece incorporada no discurso das crianças e em suas práticas, pois sabemos que as culturas infantis são construídas pela apropriação que as crianças fazem do que a cultura mais ampla thes oferece através da sua reprodução ou reinterpretação. O comportamento das crianças é regulado pelos adultos e pelos seus pares na construção simbólica e cultural dos sujeitos e de seus corpos. Se às meninas se dirige uma contenção, aos meninos parece haver uma permanente cobrança de demonstrações de virilidade. $\mathrm{O}$ controle das emoções é relativo no caso das meninas e bastante assertivo sobre a conduta dos meninos. Certamente essas generalizações não são suficientes para o entendimento da complexidade das relações existentes, porém, auxiliam a análise da formação dos sujeitos masculinos e femininos. 
O texto apresenta parte dos achados possíveis ao longo de um ano de imersão no campo de pesquisa, possibilitados pela adoção de uma perspectiva etnográfica que nos colocou diante de uma teia de significados, estes foram alguns dos fios que pude puxar. Ainda assim, cabe destacar que: "A criança transgressora desafia as normas pressupostas e coloca-as em discussão. Mostra, por suas ações, que masculinidades e feminilidades são construções sociais (...), contribuindo para fabricar sujeitos desiguais" (VIANNA e FINCO, 2009, p. 280). 


\section{REFERÊNCIAS}

ABRAmovay, Miriam. (Org.). Juventudes e Sexualidade. Brasília: Unesco, 2004.

ANDRÉ, Marli E.D.A. Cotidiano escolar e práticas sócio-pedagógicas. Em Aberto, Brasília, ano 11, n. 53, p. 28-39, jan./mar. 1992.

BAKHTIN, Mikhail. Estética da criação verbal. 6. ed. São Paulo: Martins Fontes, 2011.

BARRETO, Flavia de Oliveira; SILVESTRI, Mônica Ledo. Relações dialógicas interculturais: brinquedos e gênero. ANPED. Anais da $\mathbf{2 8}^{\mathbf{a}}$.... Caxambu: ANPED, 2005. Disponível no site <http://www.anped.org.br/reunioes/28/ textos/ge23/ge23943int.pdf>. Acesso em: 05/07/2008.

BOURDIEU, P. O Campo Científico. In: ORTIZ, Renato. (Org.). Coleção Grandes Cientistas Sociais, n. 39. São Paulo: Editora Ática, 1983.

BROUGÈRE, Gilles. A criança e a cultura lúdica. Rev. Fac. Educ., São Paulo, v. 24, n. 2, jul. 1998.

CORSARO, William A. Entrada no campo, aceitação e natureza da participação nos estudos etnográficos com crianças pequenas. Educ. Soc., Campinas, v. 26, n. 91, p. 443-464, aug. 2005.

. Reprodução interpretativa e cultura de pares. In: MÜLLER, Fernanda; CARVALHO, Ana M. (Orgs.). Teoria e Prática na pesquisa com crianças: diálogos com William Corsaro. São Paulo: Cortez, 2009. p. 31-50.

The Sociology of Childhood. California: Pine Forge Press, 1997.

DURKHEIM, Émile. Sociologia, educação e moral. Porto: Rès, 1994.

FERREIRA, Manuela. O Trabalho de Fronteira nas relações entre géneros em espaços de "brincar ao faz-de-conta". Revista Ex Aequo, Oeiras, Celta, n. 7, p. 113-128, 2002.

FOUCAULT, Michel. História da sexualidade: a vontade de saber. Rio de Janeiro: Graal, 1988. v. 1.

Vigiar e Punir. Petrópolis: Vozes, 1977.

GEERTZ, Cliford. A interpretação das culturas. Rio de Janeiro: LTC, 1989.

HALL, Stuart. A identidade cultural na pós-moderni dade. Rio de Janeiro: DP\&A, 2005.

LOURO, Guacira Lopes. Gênero, Sexualidade e Educação. Rio de Janeiro: Vozes, 1997.

Sexualidade: lições da escola. In: MEYER, D. E. E (Org.). Saúde e sexualidade na escola. Porto Alegre: Mediação, 1998. p. 85-95. (Cad. Educação Básica; 4).

MALINOWSKI, Bronisław. Introdução, objeto e método e alcance desta investigação. In: Os Argonautas do Pacífico Ocidental. São Paulo: Abril Cultural, 1976. (Col. Os Pensadores).

Os argonautas do Pacífico Ocidental: Um relato do empreendimento e da aventura dos nativos nos arquipélagos da Nova Guiné, Melanésia. São Paulo: Abril Cultural, 1978.

MATTOS, Carmen L. Guimarães; CASTRO, Paula Almeida. (Orgs.). Etnografia e educação: conceitos e usos [online]. Campina Grande: EDUEPB, 2011. Autores. 298 p. ISBN 978-85-7879-190-2. Disponível em: SciELO Books. Acesso em: 27 nov. 2017.

MOTTA, Flávia Miller Naethe. De crianças a alunos: a transição da Educação Infantil para o Ensino Fundamental. São Paulo: Cortez Editora, 2013.

OLIVEIRA, Inês Barbosa. Aprendendo nos/dos/com os cotidianos a ver/ler/ouvir/sentir o mundo. Educ. Soc., Campinas, vol. 28, n. 98, p. 47-72, jan./abr. 2007.

Estudos do cotidiano, pesquisa em educação e vida cotidiana: o desafio da coerência. ETD - Educação Temática Digital, Campinas, SP, v. 9, p. 162-184, jan. 2009. ISSN 1676-2592. Disponível em: <https://periodicos.sbu. unicamp.br/ojs/index.php/etd/article/view/1050>. Acesso em: 10 nov. 2017. Doi: <http://dx.doi.org/10.20396/etd.v9 i0.1050>.

PASSOS, Mailsa C. Pinto. Encontros cotidianos e a pesquisa em Educação: relações raciais, experiência dialógica e processos de identificação. Educ. rev., Curitiba, n. 51, p. 227-242, mar. 2014. 
SARMENTO, Manuel; GOUVEA, Maria Cristina S. (Orgs.). Estudos da infância: educação e práticas sociais. Petrópolis, RJ: Vozes, 2008.

TURNER, Victor. O Processo Ritual: Estrutura e Anti-Estrutura. Petrópolis, RJ: Vozes, 1974.

VAN GENNEP, Arnold. Os ritos de passagem. Petrópolis: Vozes, 1978.

VIANNA, Claudia; FINCO, Daniela. Meninas e meninos na Educação Infantil: uma questão de gênero e poder. Cad. Pagu [on-line], n. 33, p.265-283, 2009.

VIGOTSKI, Lev Semenovich. A formação social da mente. 6. ed. São Paulo: Martins Fontes, 1998.

\section{RESUMO}

O presente artigo trata das relações de poder e gênero entre as crianças de cinco anos de idade numa escola municipal da cidade de Três Rios, Rio de Janeiro. Apoia-se no conceito de gênero como ferramenta de análise para compreender as maneiras como são forjadas as relações de poder entre as crianças numa perspectiva etnográfica.

Palavras-chave: Educação Infantil. Gênero. Pesquisa com crianças.

\section{RESEARCH WITH CHILDREN: SOME GENDER ISSUES IN CHILDHOOD EDUCATION}

\section{ABSTRACT}

This article deals with power and gender relations among five - year - old children in a municipal school in the city of Três Rios, Rio de Janeiro. It is based on the concept of gender as a tool of analysis to understand the ways in which power relations between children take place in an ethnographic perspective.

Keywords: Childhood Education. Gender. Research with children.

\section{INVESTIGACIÓN CON NIÑOS: ALGUNAS CUESTIONES DE GÉNERO EN LA EDUCACIÓN INFANTIL}

\section{RESUMEN}

El presente artículo trata de las relaciones de poder y género entre los niños de cinco años de edad en una escuela municipal de la ciudad de Tres Rios, Río de Janeiro. Se apoya en el concepto de género como herramienta de análisis para comprender las formas como suceden las relaciones de poder entre los niños en una perspectiva etnográfica.

Palabras clave: Educación infantil. Género. Búsqueda con niños.

Submetido em: 28 de maio de 2018

Aprovado em: 30 de abril de 2019 